\title{
Allergiekinder: Keine Angst vorm Impfen!
}

\begin{abstract}
Kinder mit einer allergischen Disposition sollten grundsätzlich geimpft werden. Doch gibt es einige Ausnahmen, die beachtet werden müssen. So stellt die hochdosierte Kortikoidmedikation eine Kontraindikation dar. Auch muß auf das Vorliegen von allergenen Begleitstoffen geachtet und die Verabreichung des Impfstoffes im Einzelfall abgewogen werden.
\end{abstract}

Atopiker haben genauso einen Anspruch auf Impfschutz gemäß den Empfehlungen der ständigen Impfkommission (STIKO) des Robert-Koch-Institutes in Berlin wie alle anderen Personen, erklärte D. Schöne, Alexanderhaus-Klinik Davos. Weder bei Kindern mit allergischer Disposition noch bei solchen mit manifesten Atopien, etwa Neurodermitis, bestehe Anlaß, sie davon auszuschließen, wie mehrere Studien bestätigten. Allerdings räumte der Der-

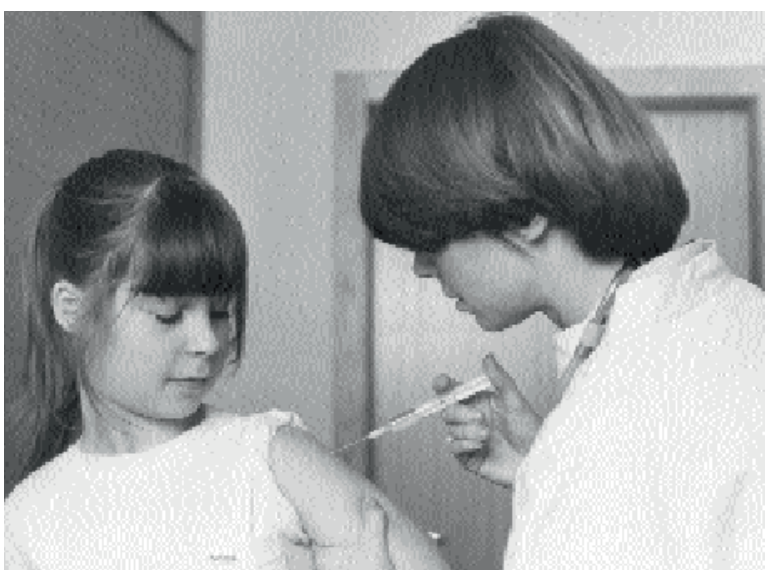

Impfungen werden von Allergiekindern in der Regel gut vertragen. Bei Vorliegen einer Ei-Allergie ist aber Vorsicht bei Impfungen z.B. gegen Gelbfieber geboten. matologe ein, daß manche atopische Kinder auf die Vakzination mit einem A u fflackern der Erkrankung reagieren.

Wann immer jedoch ein Patient unter hochdosierter (oraler) Steroidtherapie steht, sind Lebendimpfstoff e wegen der Beeinträchtigung des Abwehrsystems kontraindiziert. Aber auch bei Verwendung von To $t \mathrm{im} p$ f s t offen gilt, daß während dieser Medikation der Immunisierungserfolg nicht kalkulierbar ist.

Bekannte Überempfindlichkeiten gegenüber einem der Impfstoff-B estandteile machen es erforderlich, nach entsprechenden Ausweichpräparaten $\mathrm{zu}$ suchen, welche den betreffenden Zusatzstoff, beispielsweise Tween 80 oder Gelatine, also Rinderkollagen, nicht enthalten. Was Sensibilisierungen gegenüber Hühnereiweiß angeht, ist bei Kindern mit Allergie auf Ei-Pro- teine mit dem herkömmlichen Impfs t o ff für Masern, Mumps, Röteln im allgemeinen keine höhere Reaktionsrate zu erwarten als bei nicht allerg ischen Kindern. Die in Deutschland üblichen Vakzinen, für welche die Erreger auf Hühnerembryonen gezüchtet werden, enthalten Ei-Allergen allenfalls in Spuren.

Drei internationale Studien mit großer Teilnehmerzahl zeigten Mitte der 90er Jahre, daß der übliche Impfs t o ff ganz normal bei Allergikern verwendet werden kann. Problematisch bei Ei-Allergie können nach K. Rothert, Davos, allerdings Gelbfieberund Grippeimpfung sein: Beide enthalten sehr viel Ei-Protein; hier gibt es keine Ausweichmöglichkeiten.

Neben Kultivierungsprodukten wie Hühnereiweiß enthalten Impfstoff e weitere Stoffe mit allergenem Poten-

\section{Vorsichtsmaßnahmen bei allergiebereiten Kindern}

Kinder, von denen eine Bereitschaft zu allergischen Reaktionen bekannt ist, sollten etwa $1 / 2$ Stunde nach der Impfung in der Praxis überwacht werden - ähnlich wie bei einer Hyposensibilisierung. Anschließend wird die Einstichstelle noch einmal inspiziert.

Auch danach ist eine verzögerte Reaktion (Hautreaktion oder starke Schwellung) nicht ausgeschlossen. Nach dem heutigen Kenntnisstand darf man aber davon ausgehen, daß keine akute schwere systemische Reaktion mehr stattfindet.

Will man bei einer sehr stark ausgeprägten Ei-Allergie absolut sicher gehen, besteht die Alternative darin, Schweizer Impfstoff (der Firma Berna) für Masern, Mumps, Röteln zu verwenden, der auf menschlichen Zellen gezüchtet wird, somit völlig frei von Hühnereiweiß und allerg o 1 ogisch absolut unbedenklich ist.

tial, etwa Konservierungsstoffe wie Thiomersal, Gelatine als Stabilisator sowie Adsorbenzien wie Aluminiumhydroxid. Deshalb kann letztlich bei allen Impfstoffen eine Überreaktion stattfinden; Atopiekinder tragen aber den Experten zufolge kein höheres Risiko als alle anderen.

(wpa)

Quelle: Fortbildungsveranstaltung „Fortschritte der Allergologie, Immunologie und Dermatologie“, Davos 1998.

\section{PS: Der Gehalt an Ei-Protein in} Grippe-Impfstoff variiert mit dem Hersteller und von Jahr zu Jahr.

Laut einer jüngst erschienenen multizentrischen Studie ist bei entsprechender Indikation auch die Influenzaimpfung für kleine Ei-Allerg $i \mathrm{k}$ e $r$ ohne Gefahr, sofern man sich verg e$w i$ s s e rt hat, daß die Vakzine nicht mehr als 1,2 $\mu \mathrm{g}$ Ei-Protein pro $\mathrm{ml}$ enthält (James JM et al.: J Pediatr 133 (1998): 624-8). 